\title{
Skilled Delivery Service Utilization and Associated Factors among Mothers Who Gave Birth in the Last Two Years in Northwest Ethiopia
}

\author{
Nigus Tesfaw ${ }^{1}$, Ayu Gizachew ${ }^{1}$, Getachew Mullu Kassa ${ }^{1 *}$, Amanuel Alemu \\ Abajobir ${ }^{1,2}$
}

OPEN ACCESS

Citation: Nigus Tesfaw, Ayu Gizachew, Getachew Mullu Kassa, Amanuel Alemu Abajobir. Skilled Delivery Service Utilization and Associated Factors among Mothers Who Gave Birth in The Last Two Years in Enarje Enawga District, Northwest Ethiopia: A Community-Based Cross-Sectional Study. Ethiop J Health Sci.2017; 28 (4):423.

doi:http://dx.doi.org/10.4314/ejhs.v28i4.8 Received: December 4, 2017

Accepted: December 20, 2017

Published: July 1, 2018

Copyright: (C) 2018 Nigus Tesfaw, et al . This is an open access article distributed under the terms of the Creative Commons Attribution License, which permits unrestricted use, distribution, and reproduction in any medium, provided the original author and source are credited. Funding: Nil

Competing Interests: The authors declare that this manuscript was approved by all authors in its form and that no competing interest exists.

Affiliation and Correspondence:

${ }^{1}$ College of Health Sciences, Debre Markos University, Debre Markos, Ethiopia

${ }^{2}$ School of Public Health, The University of Queensland, Herston, Australia

*Email: gechm2005@gmail.com

\section{ABSTRACT}

BACKGROUND: Giving birth in a medical institution, under the care and supervision of trained health-care providers, reduces the risk of maternal mortality and promotes child survival. Despite this, most mothers in Ethiopia are giving birth at home. Thus, this study was conducted to assess the level of skilled delivery service use and associated factors among mothers in Enarje Enawga District, Northwest Ethiopia.

MATERIALS AND METHODS: A community-based crosssectional study design was employed to recruit a total of 777 mothers who gave birth in the last two years. Data were collected using structured questionnaire. Bi-variable and multivariable logistic regression analyses were employed to assess factors associated with skilled delivery service use. Odds ratios with 95\% confidence intervals were computed.

RESULTS: Only 156 (20.1\%) of the mothers had utilized skilled delivery service in the last two years. Mothers aged 15-24 years $(A O R=5.57)$, residing in urban areas $(A O R=1.80)$, and residing within a walking time of 16-30 minutes from health facility $(A O R=$ 3.52) were more likely to use skilled delivery practice. Additionaly, mothers who had four and more antenatal care (ANC) visits (AOR $=4.94)$ and mothers who received health education $(A O R=5.04)$ were more likely to use skilled delivery service.

CONCLUSION: The level of skilled delivery service use among mothers was low. Age, residence, distance from health facility, number of $A N C$ visits and health education were found to be associated with skilled delivery service use. Community-based health education programs regarding the risks of home delivery is necessary with a special focus on younger mothers residing in rural area.

KEYWORDS: Mother of reproductive age group, skilled delivery, associated factors, community-based cross-sectional study 


\section{INTRODUCTION}

Maternal health is a central concern both globally and nationally. Thus, improving maternal survival was one of the eight Millennium Development Goals and focuses of Sustainable development goals (SDGs) (1-3). Though mothers comprise a large proportion of a society, more than onequarter in developing countries are at higher risk of obstetric-related morbidity and mortality. Consequently, they suffer from long-term complications of pregnancy and childbirth including uterine prolapse and vesicovaginal and rectovaginal fistulae. Additionally, prolonged obstructed labor can result in infection of the pelvic organs leading to infertility and other longer-term gynecological problems $(1,4,5)$. Moreover, maternal morbidity and mortality cause considerable social and personal distress in a family, community, country and the world as a whole. Remarkably, large proportions of pregnancy-related morbidities and mortalities occur in developing nations (6), especially in subSaharan African countries including Ethiopia (69).

Globally, over 20 million mothers become pregnant every year, and about $15 \%$ of these mothers develop obstetric complications (9) such as bleeding during pregnancy, childbirth and postnatal period, infection, prolonged and obstructed labor and toxemia $(6,7,9)$. Interestingly, access to appropriate health services (e.g., skilled delivery service during pregnancy and childbirth) are an important strategy in promoting health of the mother and the baby $(8,10)$. Skilled and hygienic delivery service for the mother can reduce the risk of complications during and after labor and childbirth (10). Evidence shows that lack of access to essential obstetric care services is one of the important factors that contribute to the high burden of maternal morbidity and mortality, especially in developing countries $(6,8-10)$. The majority of these complications arise from obstructed labor, hemorrhage, sepsis and eclampsia. These complications are manageable and could be addressed by health professionals during pregnancy (i.e., mother's antenatal clinic attendance), delivery or post-partum through treatment and prompt referral (whenever necessary) $(7,10)$. Numerous studies around the world show that despite several decades of global health initiatives on maternal health, maternal mortality ratio has remained virtually unchanged over the past 17 years $(2,4-8,11-13)$.

The burden of maternal morbidity and mortality is high in Ethiopia. The rate of maternal mortality ratio (MMR) in the country during 2000, 2005 and 2011, the Ethiopian demographic and health survey (EDHS) was 871, 673 and 676 per 100,000 live births, respectively. Eventhough the rate of infant and child mortality in Ethiopia is decreasing, the progress is slow (8). In Ethiopia, the risk of death from complications relating to pregnancy and childbirth over the woman's life time is 1 in 67 , which is 2.3 times greater than equivalent estimate for developing countries ( 1 in $150)$ and 2.7 times higher than the world's estimate (1 in 180) (10).

Studies have shown that the use of skilled delivery service is one of the proven interventions in the reduction of maternal and child morbidity and mortality $(7,10)$. However, in most developing countries including Ethiopia, most deliveries occur at home in the absence of skilled birth attendants $(8,9,14-16)$. Moreover, the proportion of mothers utilizing safe delivery service in Ethiopia in general and in Amhara region in particular is very low (16-22). However, there was no previous study conducted in Enarje Enawga District on institutional delivery service use and its associated factors to tailor public health interventions, resource mobilization, planning and evaluation of maternal health services in the district.Therefore, this study was conducted to assess the level of skilled delivery service utilization and associated factors among mothers who gave birth in the last two years in Enarje Enawga District, Northwest Ethiopia.

\section{MATERIALS AND METHODS}

Study design, area and population: A community-based cross-sectional study was conducted from February to March 2015 in Enarje Enawga District. The District is located at the northwestern part of Ethiopia, about 295 kilometers from Addis Ababa, the nation's capital.

DOI: http://dx.doi.org/10.4314/ejhs.v28i4.8 
The estimated total population of the district according to the 2014 Ethiopian projected population report was 189,083 , of which 95,487 $(50.5 \%)$ were females. Reproductive age women aged 15-49 years in the district constituted about $22,916(\%$ ?). The estimated number of mothers who had children under two years old in the district was about $6050(3.2 \%)$ of the total population (23). There were seven public health centers, six private clinics and 27 health posts in the district. The source population for this study were mothers who gave birth in the last two years in Enarje Enawga District. Critically ill mothers who were unable to respond for the interview were excluded from the study.

Sample size and sampling technique: The sample was calculated using single population proportion formula. The assumptions considered were $96 \%$ confidence interval (CI), $4 \%$ margin of error, and $16 \%$ proportion of mothers who utilized skilled attendant during childbirth (from previous study) (24). A 10\% non-response rate and a design effect of 2 were also considered. Based on the above assumptions, the calculated total sample size was 777 mothers who gave birth in the last two years.

Two-stage sampling technique was used in sampling the study participants. From the total of 28 (25 rural and three urban) kebeles (smallest administrative unitw), 10 kebeles were selected by simple random sampling technique (1 from urban and nine from rural sites). The sampling frame was obtained from the district health extension workers' registration. The total number of mothers in each selected kebele was calculated by probability proportional to size allocation for each kebele to give the total number of the study participants. From each selected kebele, every $\mathrm{k}=8^{\text {th }}$ interval participants was selected using systematic random sampling technique.

Study variables and operational definitions: The dependent variable of this study was skilled delivery service utilization. The independent variables included socio-demographic characteristics, health institution related factors, ANC service-related factors and awareness about skilled delivery service. Skilled attendant is defined as a person with midwifery skills (nurse, midwife, health officer and doctor) who were trained to manage a normal delivery, to diagnose problems and to refer for obstetric complications $(6,25)$. Skilled delivery service comprises services provided at health facilities and attended by skilled attendants (25). Skilled delivery service utilization is the use of delivery services provided at health facilities and attended by skilled attendants in clinics, health centers, public and private hospitals among mothers who gave birth in the last two years for their last delivery (6).

Data collection tools andprocedure: A semistructured questionnaire adapted from different literature $(15,26)$ was used to collect the data. The questionnaire was prepared in English and then translated into Amharic (local language). It was pre-tested on $5 \%$ of the total sample in one of the non-selected kebeles. The data collectors and three supervisors (nurses) were trained, for 2 days, on data collection and ethical issues. Data collection was carried out by 10 high school completed, Amharic language speaking data collectors using face-to-face interview technique. If there was absenteeism of the respondents during data collection, three subsequent visits were attempted after which eligible mothers in the adjacent households were interviewed.

Data quality, processing and analysis: Data quality was assured through careful design and pretesting of the questionnaire, proper training of the data collectors and supervisors, close supervision, and proper handling of the data. After data collection, each form was coded separately, cleaned and entered into the computer using EpiInfo version 3.53 statistical package. Data were transferred to SPSS version 20.0 software for analysis. Descriptive statistics; namely, mean (standard deviation (SD)) for continuous variables and frequency and percent for categorical variables were used. Bi-variable and multivariable logistic regressions were carried out to find significant factors associated with skilled delivery service use. Odds ratio (OR) with $95 \% \mathrm{CI}$ and associated p-values were computed to determine the association between dependent and independent variables.

Ethics: Ethical clearance was obtained from the Research Committee of Debre Markos University,

DOI: http://dx.doi.org/10.4314/ejhs.v28i4.8 
College of Health Sciences. Letters of support were received from East Gojjam Zonal Health Department and District Administrative Office in the study area. Data were collected after getting informed consent from each study participant. All information collected from the respondents was kept confidential.

\section{RESULTS}

Socio-demographic characteristics: A total of 777 study participants were included in the study. The mean age of the study participants was 28.14 years ( $\mathrm{SD} \pm 7.12$, range: 17 to 49). Three hundred thirty-six $(43.3 \%)$ of the study participants were aged between 25 and 34 years. Four hundred twelve $(53.1 \%)$ of the study participants had no formal education. The majority, $726(93.6 \%)$, of the respondents were Orthodox Christians, and all of them were Amhara by ethnicity. Nearly three-fourths, $573(73.8 \%)$, were rural residents. More than half, 411(53\%), had family sizes between 6 and 8 (Table 1).

Health facility-related and obstetric characteristics: Five hundred thirty-three (68.7\%) of the respondents had a health facility within 30 minutes and below walking distance. Greater than half, 430(55.4\%), of the respondents had no car transportation facility (road access) to the health facilities. Nearly half, 386(49.7\%), of the participants got their first marriage at an age below 15 , and $95(12.2 \%)$ of them got their first pregnancy below the age of 15 . Two hundred sixty-three (33.9\%) of the respondents had been pregnant only once, and $8.5 \%$ had more than five pregnancies. More than a quarter, 215(27.7\%), had obstetric difficulties in previous deliveries (Table 2). The majority of the respondents, $658(84.8 \%)$, had at least one ANC follow-up for their last pregnancy, of whom, 576(87.5\%) had greater than 2 ANC visits. The majority of these mothers, 560(83.8\%), had got health education about different relevant topics (danger signs of pregnancy, nutrition during pregnancy, complication readiness and other pregnancy related services) during their ANC visit.
Table 1: Socio-demographic characteristics of mothers who gave birth in the last two years in Amhara region, Northwest Ethiopia, February to March, 2015.

\begin{tabular}{|c|c|c|}
\hline Variables & № & $\%$ \\
\hline \multicolumn{3}{|l|}{ Age } \\
\hline $15-24$ years & 234 & 30.1 \\
\hline $25-34$ years & 336 & 43.3 \\
\hline $35-44$ years & 137 & 17.7 \\
\hline $45+$ years & 69 & 8.9 \\
\hline \multicolumn{3}{|l|}{ Educational status } \\
\hline No formal education & 412 & 53.1 \\
\hline Adult education & 99 & 12.8 \\
\hline Primary school education & 173 & 22.3 \\
\hline Secondary school education & 56 & 7.2 \\
\hline College diploma and above education & 36 & 4.6 \\
\hline \multicolumn{3}{|l|}{ Marital status } \\
\hline Single & 76 & 9.8 \\
\hline Married & 670 & 86.3 \\
\hline Separated & 30 & 3.9 \\
\hline \multicolumn{3}{|l|}{ Religion } \\
\hline Orthodox & 726 & 93.6 \\
\hline Muslim & 50 & 6.4 \\
\hline \multicolumn{3}{|l|}{ Residence } \\
\hline Urban & 203 & 26.2 \\
\hline Rural & 573 & 73.8 \\
\hline \multicolumn{3}{|l|}{ Occupation } \\
\hline Government employee & 36 & 4.6 \\
\hline Merchant & 113 & 14.6 \\
\hline Farmer & 442 & 57.0 \\
\hline House wife & 185 & 23.8 \\
\hline \multicolumn{3}{|l|}{ Monthly income (ETB) } \\
\hline$<500$ ETB & 131 & 16.9 \\
\hline 501-1000 ЕТВ & 531 & 68.4 \\
\hline 1001-1500 ЕТВ & 42 & 5.4 \\
\hline 1501-2000 ЕTВ & 54 & 7.0 \\
\hline$>2000 \mathrm{ETB}$ & 18 & 2.3 \\
\hline \multicolumn{3}{|l|}{ Husband's age in year } \\
\hline $15-24$ years & 62 & 8.0 \\
\hline $25-34$ years & 299 & 38.5 \\
\hline $35-44$ years & 309 & 39.8 \\
\hline 45 years and above & 106 & 13.7 \\
\hline \multicolumn{3}{|l|}{ Husband's occupation } \\
\hline Government employee & 34 & 4.4 \\
\hline $\begin{array}{l}\text { Non-governmental organization } \\
\text { employee }\end{array}$ & 15 & 1.9 \\
\hline Merchant & 143 & 18.4 \\
\hline Farmer & 584 & 75.3 \\
\hline \multicolumn{3}{|l|}{ Husband's educational status } \\
\hline No formal education & 278 & 35.8 \\
\hline Adult education & 180 & 23.2 \\
\hline Primary school education & 254 & 32.7 \\
\hline Secondary school education & 25 & 3.2 \\
\hline College diploma and above education & 39 & 5.0 \\
\hline \multicolumn{3}{|l|}{ Family size } \\
\hline $3-5$ & 257 & 33.1 \\
\hline $6-8$ & 411 & 53.0 \\
\hline 8 and above & 108 & 13.9 \\
\hline
\end{tabular}


Table 2: Obstetric characteristics of mothers who gave birth in the last two years in Enarje Enawga woreda, East Gojjam, Amhara region, northwest Ethiopia, February to March, 2015.

\begin{tabular}{|c|c|c|}
\hline Variables & No & $\%$ \\
\hline \multicolumn{3}{|l|}{ Age at first marriage (in years) } \\
\hline$<15$ & 386 & 49.7 \\
\hline $15-24$ & 373 & 48.1 \\
\hline $25-34$ & 17 & 2.2 \\
\hline \multicolumn{3}{|l|}{ Age at first pregnancy (in years) } \\
\hline$<15$ & 95 & 12.2 \\
\hline $15-24$ & 565 & 72.8 \\
\hline $25-34$ & 116 & 14.9 \\
\hline \multicolumn{3}{|l|}{ Age at last pregnancy (in years) } \\
\hline $15-24$ & 288 & 37.1 \\
\hline $25-34$ & 323 & 41.7 \\
\hline $35-44$ & 115 & 14.8 \\
\hline $45+$ & 50 & 6.4 \\
\hline \multicolumn{3}{|l|}{ Gravidity/total number of pregnancy } \\
\hline One & 263 & 33.9 \\
\hline Two - five & 447 & 57.6 \\
\hline Greater than five & 66 & 8.5 \\
\hline \multicolumn{3}{|l|}{ Parity/total number of live births } \\
\hline One & 328 & 42.3 \\
\hline Two - five & 397 & 51.1 \\
\hline Greater than five & 51 & 6.6 \\
\hline \multicolumn{3}{|c|}{$\begin{array}{l}\text { Obstetric difficulties in previous deliveries (for other than the last } \\
\text { pregnancy) }\end{array}$} \\
\hline Yes & 215 & 27.7 \\
\hline No & 561 & 72.3 \\
\hline \multicolumn{3}{|c|}{$\begin{array}{l}\text { Specific measures taken for obstetric difficulties in previous deliveries } \\
(\mathrm{n}=195)\end{array}$} \\
\hline Nothing & 31 & 15.9 \\
\hline Traditional method (massage, herbs) & 58 & 29.7 \\
\hline Visit health institution & 106 & 54.4 \\
\hline \multicolumn{3}{|l|}{ Type of the health institute } \\
\hline Health Center & 362 & 46.6 \\
\hline Private Clinic & 12 & 1.5 \\
\hline Health post & 402 & 51.8 \\
\hline \multicolumn{3}{|c|}{ Distance of the health institute from home by walking (in minutes) } \\
\hline Below 15 & 205 & 26.4 \\
\hline $16-30$ & 328 & 42.3 \\
\hline $31-45$ & 64 & 8.2 \\
\hline $46-60$ & 74 & 9.5 \\
\hline $61-120$ & 105 & 13.6 \\
\hline \multicolumn{3}{|c|}{ Presence of car transport to the health institute } \\
\hline Yes & 346 & 44.6 \\
\hline No & 430 & 55.4 \\
\hline \multicolumn{3}{|c|}{ Presence of delivery service at the health institute } \\
\hline Yes & 622 & 80.2 \\
\hline No & 154 & 19.8 \\
\hline
\end{tabular}

DOI: http://dx.doi.org/10.4314/ejhs.v28i4.8 
Skilled delivery service utilization: Almost all of the respondents, $767(98.8 \%$ ), believed that there was a difference between giving birth at home and health facility. However, 54(7.0\%) of these mothers thought home delivery is better for privacy and comfort, safety, cleanliness and some cultural practices held at home. Health workers, relatives, friends, neighbors and media were mentioned as sources of information regarding the benefits of institutional delivery. However, more than 1 in 10 mothers, 108(13.9\%), had no information about the benefits of institutional delivery.

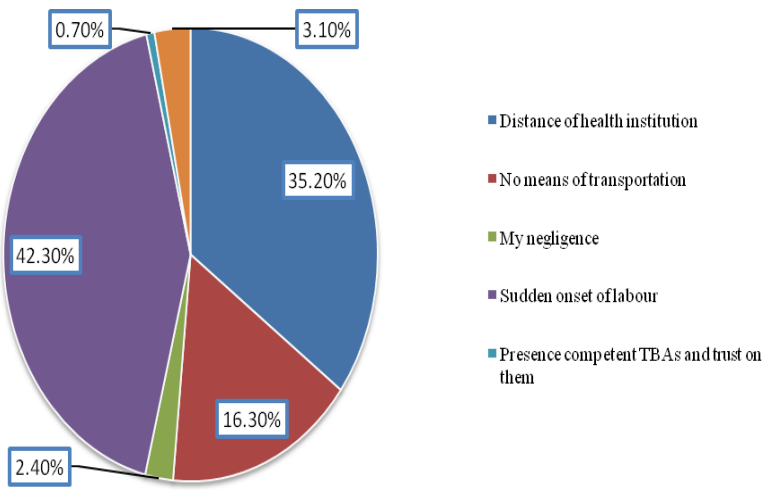

Five hundred forty-five $(70.2 \%)$ of the mothers had at least one institutional delivery during their previous (other than the last) deliveries. One hundred seventy-one $(22.0 \%)$ of the mothers had given childbirth at health institutions during their last delivery. Fifteen $(1.9 \%)$ mothers delivered at health posts (which were not considered as skilled delivery sites). Thus, only $156(20.1 \%)$ of the mothers had utilized skilled delivery service for their last child at health facility. The distance of health institution from their home, lack of means of transportation, negligence, perceived presence and trust on traditional birth attendants (TBAs) and lack of knowledge were the main reasons mentioned for home delivery (Figure 1).

Figure 1: Reasons of the women for choosing home delivery among mothers who gave birth in the last two years in Enarje Enawgaworeda, East Gojjam, Amhara region, northwest Ethiopia, February to March/2015.

TBAs, neighbors and relatives were care providers during home deliveries for $16.9 \%, 24.9 \%$ and $24.6 \%$ of the mothers, respectively. Ninety (11.6\%) mothers delivered at their home, without any assistance (Table 3).

Factors associated with skilled delivery service utilization: Multiple logistic regression analysis was carried out to assess the independent association of different factors with skilled delivery service use. According to the multiple logistic regression analysis, mothers aged 15-24 years compared to those aged 45 and above years $(\mathrm{AOR}=5.57 ; 95 \% \mathrm{CI}$ : $1.43,21.67)$, who lived in urban areas $(\mathrm{AOR}=1.80$; 95\%CI:1.02, 3.17), who resided within a walking distance of 16-30 minutes from ahealth facility when compared to thosewalking $1-2$ hours $(\mathrm{AOR}=3.52$; 95\%CI: 1.19-10.45) had more odds of using skilled delivery service. Additionally, mothers who had four and above ANC visits (AOR=4.94; 95\%CI: 1.89 , 12.94), and mothers who had received health education on skilled delivery and related issues (AOR=5.04; 95\%CI: 1.99, 12.78) were more likely to use skilled delivery service (Table 4).

\section{DISCUSSION}

This cross-sectional study was conducted to assess skilled delivery service utilization among mothers who gave birth in the last two years in Enarje Enawga District, Amhara Region, Ethiopia. The finding of this study showed that $84.8 \%$ of the mothers had ANC follow-up for their last pregnancy, the majority having had greater than

two visits. This finding is higher than the 2011 Ethiopian demographic and health survey (EDHS), where $34 \%$ of mothers who gave birth in the last five years preceding the survey used antenatal care (27).

The study showed that the level of skilled delivery service utilization was low (only 20.1\%) in the district. This proportion is very low, even the lowest when compared with other low-income and developing countries. The percentage of skilled delivery for Africa was $48 \%$, and it was $49 \%$ for Asia(4). However, the current finding is a little bit higher as compared to EDHS 2014(16\%) (28) and other community-based cross-sectional surveys done in Munisa District, Arsi Zone, Oromia Region (12.3\%)(14), in Tigray (3.6\%) (13) and in rural Jimma, Horro District (8\%)(25). The presence of global, regional and national efforts for the establishment of health centers and

DOI: http://dx.doi.org/10.4314/ejhs.v28i4.8 
the recent radically increased access to ambulance service for maternal services could explain these differences. Another possible explanation for this could be the differences in socio-demographic and related factors of the participants.That is, the difference in study areas and socio-demographic status of the participants might be the reason for the variation in the findings. In line with prior studies (13-15,25), the findings of this study showed health facility-related enabling factors such as nearby health facility and health education contributed for using skilled delivery services.

Table 3: Skilled delivery service utilization among mothers who gave birth in the last two years in Enarje Enawga woreda, East Gojjam, Amhara region, northwest Ethiopia, February to March, 2015

\begin{tabular}{|c|c|c|}
\hline Variables & No & $\%$ \\
\hline \multicolumn{3}{|c|}{ There is difference between giving birth at home and health facility } \\
\hline Yes & 767 & 98.8 \\
\hline No & 9 & 1.2 \\
\hline \multicolumn{3}{|l|}{ Which one do you think best? } \\
\hline Health facility & 722 & 93.0 \\
\hline Home & 54 & 7.0 \\
\hline \multicolumn{3}{|c|}{ Information about the benefit of delivery in health institution } \\
\hline Yes & 660 & 85.1 \\
\hline No & 116 & 14.9 \\
\hline \multicolumn{3}{|l|}{ History of delivery at health institution } \\
\hline Yes & 545 & 70.2 \\
\hline No & 231 & 29.8 \\
\hline \multicolumn{3}{|c|}{ Place where the last delivery was taken place } \\
\hline Health facility & 171 & 22.0 \\
\hline Home & 605 & 78.0 \\
\hline \multicolumn{3}{|c|}{ Type of the health facility where the last delivery was taken place } \\
\hline Hospital & 14 & 8.2 \\
\hline Health centre & 142 & 83.0 \\
\hline Health post & 15 & 1.9 \\
\hline \multicolumn{3}{|c|}{ Satisfied with delivery service at health facility } \\
\hline Yes & 158 & 92.4 \\
\hline No & 13 & 7.6 \\
\hline \multicolumn{3}{|c|}{ Reasons for no satisfaction in delivering at health facility } \\
\hline Long waiting time & 7 & 17.9 \\
\hline Unable to perform cultural ceremonies & 13 & 33.3 \\
\hline Charged for the services & 6 & 15.4 \\
\hline Lack of privacy & 13 & 33.3 \\
\hline \multicolumn{3}{|c|}{ Who assisted you during delivering at home? } \\
\hline Traditional birth attendant & 131 & 16.9 \\
\hline Neighbours & 193 & 24.9 \\
\hline Relatives & 191 & 24.6 \\
\hline No one/myself & 90 & 11.6 \\
\hline \multicolumn{3}{|l|}{ Skilled delivery service utilization } \\
\hline Yes & 156 & 20.1 \\
\hline No & 620 & 79.9 \\
\hline
\end{tabular}

DOI: http://dx.doi.org/10.4314/ejhs.v28i4.8 
Table 4: Factors associated with skilled delivery service utilization among mothers who gave birth in the last two years in Enarje Enawga district, East Gojjam, Amhara region, Northwest Ethiopia, February to March, 2015

\begin{tabular}{|c|c|c|c|c|c|}
\hline \multirow{2}{*}{ Variables } & \multicolumn{2}{|c|}{$\begin{array}{l}\text { Skilled delivery } \\
\text { service utilization }\end{array}$} & \multirow[b]{2}{*}{$\begin{array}{l}\text { Crude OR } \\
(95 \% \mathrm{CI})\end{array}$} & \multirow{2}{*}{$\begin{array}{l}\text { Adjusted OR } \\
(95 \% \mathrm{CI})\end{array}$} & \multirow[b]{2}{*}{ p-value } \\
\hline & Yes & No & & & \\
\hline \multicolumn{6}{|l|}{ Age in years } \\
\hline $15-24$ & 61 & 173 & $2.73(1.04,7.15)$ & $5.57(1.43,21.67)$ & .013 \\
\hline $25-34$ & 57 & 279 & $1.85(0.71,4.87)$ & $3.75(1.03,13.66)$ & .610 \\
\hline $35-44$ & 21 & 116 & $1.56(0.54,4.50)$ & $4.41(1.02,19.05)$ & .680 \\
\hline $45+$ & 5 & 64 & 1 & 1 & \\
\hline \multicolumn{6}{|l|}{ Residence } \\
\hline Urban & 58 & 145 & $2.27(1.55,3.32)$ & $1.80(1.02,3.17)$ & .047 \\
\hline Rural & 86 & 487 & 1 & 1 & \\
\hline \multicolumn{6}{|c|}{$\begin{array}{l}\text { Distance from health facility to home in } \\
\text { minutes }\end{array}$} \\
\hline Below 15 & 53 & 152 & $5.76(2.38,13.89)$ & $3.52(1.19,10.45)$ & .044 \\
\hline $16-30$ & 66 & 262 & $4.16(1.77,9.89)$ & $3.09(1.04,9.13)$ & .035 \\
\hline $31-45$ & 10 & 54 & $3.06(1.05,8.84)$ & $2.47(0.64,9.57)$ & .169 \\
\hline $46-60$ & 9 & 65 & $2.29(0.78,6.72)$ & $1.48(0.39,5.69)$ & .030 \\
\hline $61-120$ & 6 & 99 & 1 & 1 & \\
\hline \multicolumn{6}{|c|}{$\begin{array}{l}\text { Obstetric difficulties in previous } \\
\text { deliveries }\end{array}$} \\
\hline Yes & 57 & 158 & $2.00(1.35,2.87)$ & $2.86(1.70,4.80)$ & $<.001$ \\
\hline No & 87 & 474 & 1 & 1 & \\
\hline \multicolumn{6}{|c|}{ ANC follow up for the last pregnancy } \\
\hline Yes & 131 & 531 & $1.92(1.04,3.52)$ & $0.06(0.01,0.34)$ & .003 \\
\hline No & 13 & 101 & 1 & 1 & \\
\hline \multicolumn{6}{|l|}{ Number of ANC visits } \\
\hline One & 6 & 76 & 1 & 1 & \\
\hline Two & 12 & 70 & $2.17(0.77,6.10)$ & $3.19(0.98,10.34)$ & .001 \\
\hline Three & 27 & 131 & $2.61(1.03,6.61)$ & $4.34(1.53,12.27)$ & \\
\hline Four and above & 87 & 259 & $4.26(1.79,10.11)$ & $4.94(1.89,12.94)$ & \\
\hline \multicolumn{6}{|c|}{$\begin{array}{l}\text { Provision of health education at ANC } \\
\text { visit/s }\end{array}$} \\
\hline Yes & 126 & 434 & $4.93(2.12,11.51)$ & $5.04(1.99,12.78)$ & .001 \\
\hline No & 6 & 102 & 1 & 1 & \\
\hline \multicolumn{6}{|c|}{$\begin{array}{l}\text { Information about the benefit of delivery } \\
\text { in health institution }\end{array}$} \\
\hline Yes & 135 & 533 & $2.77(1.37,5.66)$ & $2.77(1.03,7.41)$ & .044 \\
\hline No & 9 & 99 & 1 & 1 & \\
\hline
\end{tabular}

Mothers aged 15-24 years were almost six times more likely to utilize the service compared to mothers aged 45 years and above. This might be because the younger mothers can have higher educational status, awareness about benefits of skilled delivery service and risks of home delivery. Moreover, most of the mothers in this age group had lower parity than older mother, and this may decrease mother's confidence and experience to deliver at home.These findings are in line with studies done in Arsi Zone, South-East
Ethiopia, and in Dodota District, Oromia Regional State, Ethiopia $(16,24)$.

The findings of this study also showed that mothers who resided in the urban areas are more likely to deliver in health institutions assisted by skilled professionals compared with mothers from rural areas. This might be because rural mothers may have less access to the health facilities and lack of awareness and information. This finding is in line with the EDHS 2011 report and studies

DOI: http://dx.doi.org/10.4314/ejhs.v28i4.8 
conducted in several areas of the country and elsewhere (4, 13-15, 25-27).

Distance of the health institute from mother's home was strongly associated with skilled delivery service utilization. As documented by various studies $(4,13-15,26)$ and with apparent justification, mothers whose homes were 15 minutes and below walking distance from health facilities were more likely to use skilled delivery service. Another factor affecting the use of health care service for delivery is the presence of obstetric difficulties in previous deliveries. These findings are also similar with studies conducted in North Gondar (Northern Ethiopia) and in Dodota District, Oromia Regional State, Ethiopia $(16,29)$. The fear associated with prior difficulties during labor and delivery may force these mothers to seek care early and to take necessary precautions to prevent problems.

ANC follow-up during pregnancy is another important factor for utilization of skilled delivery service. In agreement with previous studies (14$16,26,29)$, those mothers who had at list one ANC visit during their last pregnancy were more likely to deliver at ahealth facility with skilled attendant than those mother who had not any ANC follow-up. This may be because contact with the skilled providers during pregnancies gave a chance for the mother to have a better understanding of obstetric danger signs and the importance of skilled attendant during childbirth. Moreover, mothers who had four and above visits were four times more likely to utilize skilled delivery service compared with mothers who had only one visit. This might be because as the number of ANC visit increases, there will be a higher probability to have information and attitude towards the importance of skilled attendant during childbirth which in turn increase the utilization of services. Similarly, mothers with history of institutional delivery had a higher chance of delivering at health institution with the help of skilled delivery attendant.

This study, however, showed inconsistent findings with previous similar studies. For example, even if it was found to have association in the bivariate analysis, educational status of the mother as well as the husband were not significant factors for skilled delivery service utilization. Moreover, the study may be limited by recall bias due to its cross-sectional nature.

Responsible bodies and health planners at the district health offices need more efforts to educate and raise awareness of mothers and their families about risks of home delivery and benefits of skilled delivery service. This may need a focus on scaling up antenatal care follow-up and transportation facility that may provide an opportunity to inform pregnancy-related complications. Special focus should also be given to mothers residing in rural areas. Further studies are required to ascertain whether other unstudied factors may have contributed on skilled delivery service utilization of mothers.

\section{ACKNOWLEDGEMENTS}

We would like to express our sincere gratitude to Debre Markos University for providing us the opportunity to conduct this research. We would also like to express our grateful thanks for the contributions made by study participants, data collectors, supervisors and staffs of Enarje Enawga District Health Office.

\section{REFERENCES}

1. United Nations. The millennium Declaration, Resolutions. United Nations: New York. 2000.

2. International Information Support Center: Mother and child health. 2008.

3. United Nations General Assembly. Transforming our world: The 2030 agenda for sustainable development. A/RES/70/1, 21 October; 2015.

4. WHO: World health statistics 2011. [online] 2011.

http://www.who.int/whosis/whostat/2011/en

5. Esena RK, Sappor M-M. Factors associated with the utilization of skilled delivery services in the Ga East Municipality of Ghana Part 2: barriers to skilled delivery. Int $J$ Sci Tech Res. 2013;2(8):195-207.

6. Mehari A. Levels and Determinants of Use of Institutional Delivery Care Services among Women of Childbearing Age in Ethiopia: Analysis of EDHS 2000 and 2005 Data. ICF International Calverton, Maryland, USA 2013.

DOI: http://dx.doi.org/10.4314/ejhs.v28i4.8 
7. UNFPA. Challenges in achieving the MDG for maternal mortality. In-depth Analysis of the EDHS 2000-2011: Trends in Maternal Health in Ethiopia. December 2012.

8. CSA. Ethiopia Demographic and Health Survey, Preliminary Report, 2011. Ethiopia: Central Statistical Agency Addis Ababa 2011.

9. Exavery A, Kanté AM, Njozi M, Tani K, Doctor $\mathrm{HV}$, Hingora A, et al. Access to institutional delivery care and reasons for home delivery in three districts of Tanzania. International journal for equity in health. 2014;13(1):48.

10. WHO. Standards for maternal and neonatal care. Geneva: WHO. 2006.

11. WHO. Trends in Maternal Mortality: 1990 to 2010 Estimates developed by WHO, UNICEF, UNFPA and The World Bank. Geneva. 2012.

12. WHO: Maternal Health in Africa_factsheet 2013.

13. Tsegay $\mathrm{Y}$, Gebrehiwot $\mathrm{T}$, Goicolea I, Edin K, Lemma H, San Sebastian M. Determinants of antenatal and delivery care utilization in Tigray region, Ethiopia: a cross-sectional study. International journal for equity in health. 2013;12(1):30.

14. Amano A, Gebeyehu A, Birhanu Z. Institutional delivery service utilization in Munisa Woreda, South East Ethiopia: a community based crosssectional study. BMC pregnancy and childbirth. 2012;12:105.

15. Teferra AS, Alemu FM, Woldeyohannes SM. Institutional delivery service utilization and associated factors among mothers who gave birth in the last 12 months in Sekela District, north west of Ethiopia: a community-based cross sectional study. BMC pregnancy and childbirth. 2012;12:74.

16. Fikre AA, Demissie M. Prevalence of institutional delivery and associated factors in Dodota Woreda (district), Oromia regional state, Ethiopia. Reprod Health. 2012;9:33.

17. Abeje G, Azage M, Setegn T. Factors associated with Institutional delivery service utilization among mothers in Bahir Dar City administration, Amhara region: a community based cross sectional study. Reprod Health. 2014;11:22.

18. Alemayehu M, Mekonnen W. The Prevalence of Skilled Birth Attendant Utilization and Its Correlates in North West Ethiopia. BioMed research international. 2015;2015:436938.

19. Arba MA, Darebo TD, Koyira MM. Institutional Delivery Service Utilization among Women from Rural Districts of Wolaita and Dawro Zones, Southern Ethiopia; a Community Based Cross-Sectional Study. PloS one. 2016;11(3):e0151082.

20. Demilew YM, Gebregergs GB, Negusie AA. Factors associated with institutional delivery in Dangila district, North West Ethiopia: a crosssectional study. African health sciences. 2016;16(1):10-7.

21. Habte F, Demissie M. Magnitude and factors associated with institutional delivery service utilization among childbearing mothers in Cheha district, Gurage zone, SNNPR, Ethiopia: a community based cross sectional study. BMC pregnancy and childbirth. 2015;15:299.

22. Hailemariam T, Berhanu K. Factors Influencing Institutional Child Birth among Women in Aynalem Kebelle, Mekelle, Tigray, Ethiopia. Journal of Medicine. 2016;6(2):21-7.

23. CSA. Population and housing census of Ethiopia. Result for Amhara Region, November 2007; 2: 1-72.

24. Abera M, G/Mariam A, Belachew T. Predictors of safe delivery service utilization in Arsi Zone, South-East Ethiopia. Ethiopian journal of health sciences. 2011;21(3).

25. Zegeye K, Gebeyehu A, Melese T. The role of geographical access in the Utilization of institutional delivery service in rural Jimma Horro District, Southwest Ethiopia. Prim Health Care. 2014;4(1):2167-1079.1000150.

26. Wolelie A, Aychiluhm M, Awoke W. Institutional delivery service utilization and associated factors in Banja District, Awie Zone, Amhara Regional Sate, Ethiopia. Open Journal of Epidemiology. 2014;4(01):30.

27. Central Statistical Agency/Ethiopia, ICF International. Ethiopia Demographic and Health Survey 2011. Addis Ababa, Ethiopia: Central Statistical Agency/Ethiopia and ICF International; 2012.

28. Central Statistical Agency [Ethiopia]. 2014. Ethiopia Mini Demographic and Health Survey 2014. Addis Ababa, Ethiopia.

29. Nigussie M, Mariam DH, Mitike G. Assessment of safe delivery service utilization among women of childbearing age in north Gondar Zone, North West Ethiopia. Ethiopian Journal of health development. 2004;18(3):145-52. 